\title{
Imaging of Cholangiocarcinoma
}

\author{
Ronald S. Arellano, MD ${ }^{1}$ Dushyant V. Sahani, MD² \\ ${ }^{1}$ Division of Interventional Radiology, Department of Radiology, \\ Massachusetts General Hospital, Harvard Medical School, Boston, \\ Massachusetts \\ 2 Division of Abdominal Imaging, Department of Radiology, \\ Massachusetts General Hospital, Harvard Medical School, Boston, \\ Massachusetts
}

Dig Dis Interv 2017;1:8-13.

\begin{abstract}
Address for correspondence Ronald S. Arellano, MD, Division of Interventional Radiology, Department of Radiology, Massachusetts General Hospital, Harvard Medical School, 55 Fruit Street, GRB 293, Boston, MA 02114 (e-mail: rarellano@mgh.harvard.edu).
\end{abstract}

\author{
Abstract \\ Keywords \\ - cholangiocarcinoma \\ - magnetic resonance \\ imaging \\ - cholangiography \\ - computed \\ tomography
}

Cross-section imaging plays an increasingly important role in the evaluation and diagnosis of cholangiocarcinoma (CC). CCs can have varied radiological appearances, depending on their location, morphology, as well as their histological characteristics. An awareness of the varied imaging manifestations of $\mathrm{CC}$ and its accurate diagnosis are necessary to direct appropriate management. Recent advances in imaging techniques, histological assessment, molecular imaging, surgical techniques, and radiation therapy have all revitalized interest in the diagnosis and management of CCs.

Cholangiocarcinoma (CC) originates from epithelial cells of the biliary tree. They account for approximately 10 to $15 \%$ of all hepatobiliary malignancies, second only to hepatocellular carcinoma (HCC). ${ }^{1}$ The incidence rates of CC vary among different geographic locales, according to diverse risk factors in different parts of the world. ${ }^{2}$ The development of CC is associated with conditions that result in hepatobiliary inflammation and cholestasis, including primary sclerosing cholangitis, choledochal cysts, hepatolithiasis, and parasitic infections. ${ }^{2-5}$ The vast majority (95\%) of CCs are adenocarcinomas, but less common histologic types have also been reported. ${ }^{6}$ Men tend to be affected 1.5 times more commonly than women. ${ }^{2}$

CCs are classified into two anatomically distinct subtypes: intrahepatic CC (ICC) and extrahepatic CC (ECC). ${ }^{7}$ ICCs are further characterized as either perihilar or peripheral. ${ }^{8}$ Recent studies have suggested further subtyping of ICC into two distinct histological types, based on mucin production and immunophenotypes. ${ }^{9}$ As the name implies, perihilar CC develops at the level of bifurcation of the left and right hepatic ducts, whereas peripheral CC arises more distally, usually from more peripherally located ducts. ${ }^{10,11}$ Growth patterns have been described as mass forming (most common), periductal, intraductal, or mixed. ${ }^{12-14}$ Various staging systems have been

received

November 14, 2016 accepted after revision January 30, 2017 published online March 22, 2017 developed in an attempt to either describe disease extent and/or surgical candidates. The Bismuth-Corlette's classification focuses on the extent of tumor invasion into the biliary tree. ${ }^{15}$ The American Joint Committee on Cancer/International Union Against Cancer system is based on the pathological TNM staging. ${ }^{13}$ The Memorial Sloan Kettering system attempts to classify tumors based on factors related to local extension of tumor, location of bile duct involvement, and presence of portal vein invasion. ${ }^{14}$

The overall prognosis of $\mathrm{CC}$ is poor, and surgery offers the only potential for cure. Surgical resection with microscopically negative margins is the objective for cure and offers the best long-term survival. ${ }^{16-19}$ Unfortunately, up to 20 to $50 \%$ of patients are deemed unresectable at presentation due to advanced disease. Factors that preclude surgical resection include bilateral ductal involvement to the level of the second order bile ducts, tumor involvement of the proper hepatic artery, bilateral hepatic arteries, main portal vein, metastatic lymphadenopathy, or peritoneal carcinomatosis. ${ }^{20,21}$ Nonsurgical treatment options differ depending on the location, stage, and extent of disease. Because many patients present clinically with advanced disease, treatment goals are often directed toward mitigating the consequences of biliary obstruction. Relief of biliary obstruction can be achieved by biliary drainage
Copyright $\odot 2017$ by Thieme Medical Publishers, Inc., 333 Seventh Avenue, New York, NY 10001, USA Tel: +1(212) 584-4662.
Dol https://doi.org/ 10.1055/s-0037-1599255. ISSN 2472-8721.
Interventions; Guest Editor, Ronald S. Arellano, MD 
(endoscopic or percutaneous), biliary stenting, and surgical bypass. Emerging technologies such photodynamic therapy, transarterial chemo- or radioembolization, and thermal ablation may be considered in select cases. ${ }^{22-26}$ Liver transplantation for CC is controversial, though recent studies suggest it may have a role for selected patients with early stage disease. ${ }^{27-29}$ Adjuvant chemotherapy may extend survival following surgical resection or in cases of macroscopic residual disease or recurrence. ${ }^{30}$ Because the ideal strategy for management of CC begins with accurate diagnosis, this review will primarily focus on the imaging features of CC.

\section{Imaging Modalities}

\section{Ultrasound}

Transabdominal ultrasound is a valuable and widely available screening tool for evaluating patients with suspected biliary pathology (-Fig. 1)..$^{8,31-33}$ Sonographic findings commonly encountered in CC included biliary dilatation, often associated with lobar atrophy. Dilatation of the biliary tree with abrupt cutoff in duct calibers the most common sonographic finding of CC. Owing to their location at the confluence of the left and right ducts, Klatskin's tumors cause segmental dilatation of the left and hepatic ducts, often in association with lobar atrophy. Although ultrasound is often helpful to establish the level of intrahepatic biliary obstruction, a discrete mass is infrequently identified. ${ }^{33}$

The sonographic appearances of CCs are variable, ranging from hypoechoic to mixed or hyperechoic echogenicity. ${ }^{34,35}$ When a mass is detected, US alone cannot provide the specificity for detecting CC, as mass-forming lesions may mimic other tumors such as hepatoma or metastases. ${ }^{36}$ Color Doppler imaging is helpful in distinguishing vessels from dilated ducts and in establishing the patency of intrahepatic vessels, especially the portal vein. ${ }^{33}$

\section{Computed Tomography}

Computed tomography (CT) is the preferred noninvasive diagnostic tool for evaluation of CC (-Fig. 2). ${ }^{37}$ CT offers anatomic resolution that is superior to ultrasound and allows evaluation of the level and extent of biliary obstruction. Furthermore, CT allows assessment of nonbiliary/hepatic structures, such as regional lymph nodes or omentum which can be involved by carcinomatosis. ${ }^{38-41}$ Optimal contrastenhanced CT (CECT) images are obtained using a triphasic imaging protocol including arterial, portal venous, and delayed phases. Intravenous (IV) contrast is injected at the rate of approximately 3 to $5 \mathrm{~mL} / \mathrm{s}$, with arterial phase images obtained at 20 to 30 seconds following the administration of IV contrast. Subsequently, portal-venous phase images are obtained 60 to 70 seconds later, followed by acquisition of delayed images 5 minutes after the contrast bolus. In contrast to HCC, CCs are typically hypoattenuating during arterial phase imaging. On portal-venous phases, CCs become hyperattenuating relative to normal hepatic parenchyma on delayed phase imaging. ${ }^{42-44}$ Associated lobar retraction is a common CT finding of $\mathrm{CC}^{44}$ In addition, multiplanar reconstructions in coronal and sagittal planes provide additional information regarding variant vascular anatomy and presence or absence of vascular encasement. ${ }^{45,46} \mathrm{CT}$ cholangiography with IV agents allows noninvasive assessment of the biliary tree. ${ }^{47-50}$ Volume-rendered CT cholangiography offers a noninvasive opportunity to assess the biliary tree but is limited in patients with obstructive hyperbilirubinemia. ${ }^{51,52}$ Newer magnetic resonance imaging (MRI) contrast agents may be better suited for cholangiography analysis.

\section{Magnetic Resonance Imaging}

MRI is another valuable diagnostic imaging tool for assessment of CC. ${ }^{53}$ On T1-weighted imaging (T1WI), mass-forming CCs are hypo- to isointense relative to normal hepatic tissue and hyperintense on T2-weighted imaging (T2WI). Following IV contrast administration, CCs follow an enhancement pattern similar to CECT with little tumoral enhancement on arterial phase images followed by delayed enhancement on delayed phase images. ${ }^{54-58}$ The presence of satellite nodules confers a poor prognosis and usually renders a patient inoperable. ${ }^{59,60}$ Intraductal CC shows a variety of
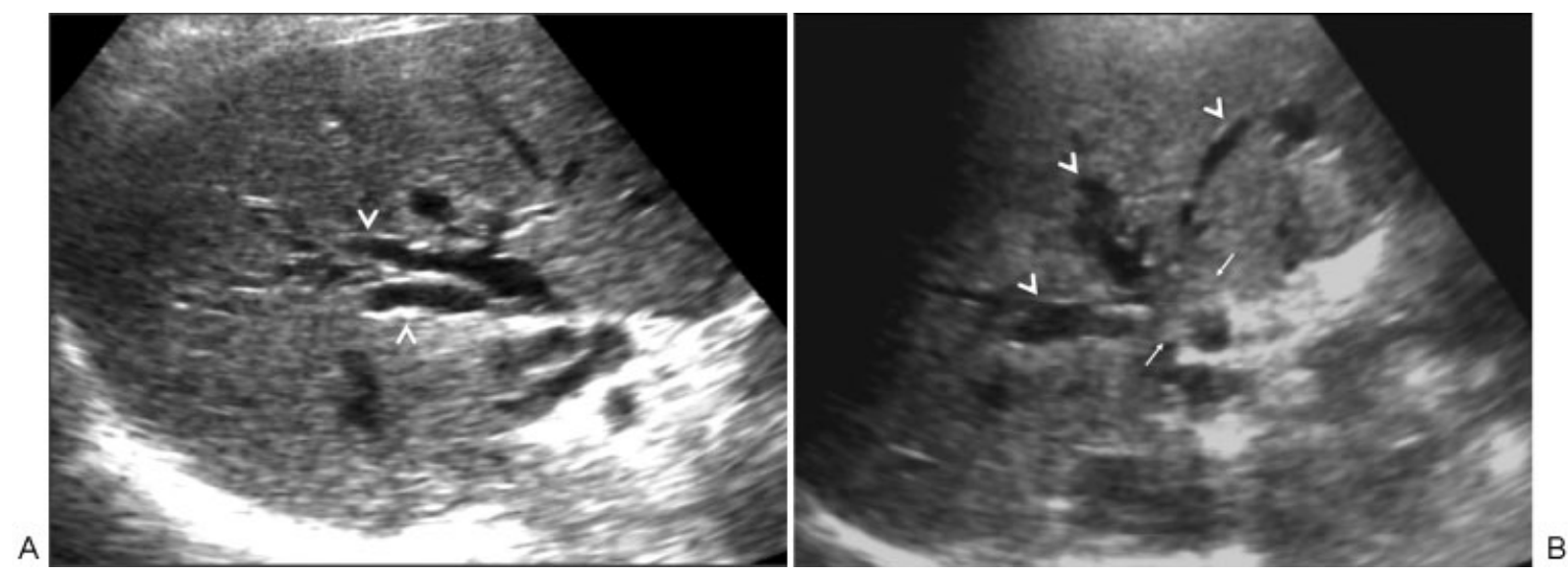

Fig. 1 (A) Transabdominal ultrasound image that shows intrahepatic biliary duct dilatation (white arrowheads). (B) Transabdominal ultrasound image that shows isoechoic soft tissue mass at the porta hepatis (white arrows), consistent with cholangiocarcinoma. Arrowheads indicate dilated bile ducts. 


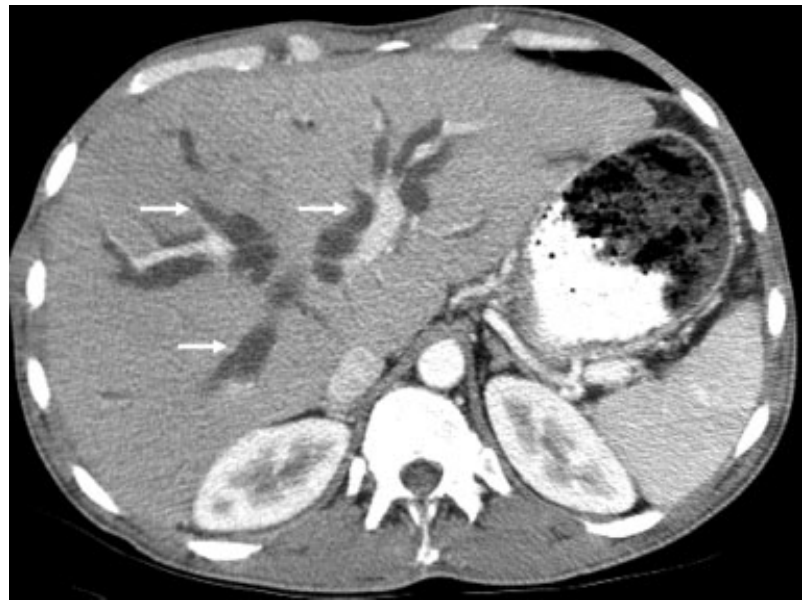

Fig. 2 Contrast material-enhanced CT scan of the liver that demonstrates dilatation of the left and right biliary radicals (white arrows). $\mathrm{CT}$, computed tomography.

imaging features depending on its growth characteristics and can manifest on MRI as diffuse infiltrating with severe duct ectasia, an intraductal polypoid-like mass with focal duct dilatation, cast-like lesions, or as a focal stricture. ${ }^{59,61,62}$ Intraductal lesions are hypo- to isointense on T1WI and are usually slightly hyperintense on T2WI. Magnetic resonance cholangiopancreatography (MRCP) supplements standard MRI by providing noninvasive evaluation of the biliary anatomy ${ }^{63,64}$ (- Fig. 3). MRCP is associated with high sensitivity and specificity for localizing the location of biliary obstruction. ${ }^{65,66}$ Magnetic resonance angiography, similar to CECT, offers detailed assessment of the anatomic relationship of tumors to hepatic vasculature ( - Fig. 4)..$^{67-69}$ Diffusion-weighted imaging also adds higher sensitivity and diagnostic accuracy for assessing biliary obstruction or bile duct injury following liver transplant. ${ }^{70,71}$

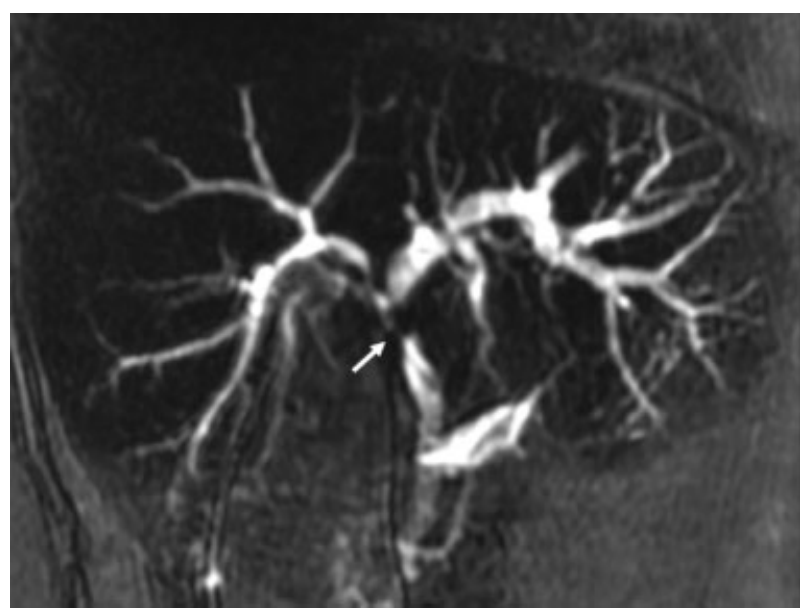

Fig. 3 Magnetic resonance cholangiogram that demonstrates malignant hilar strictures (white arrow).
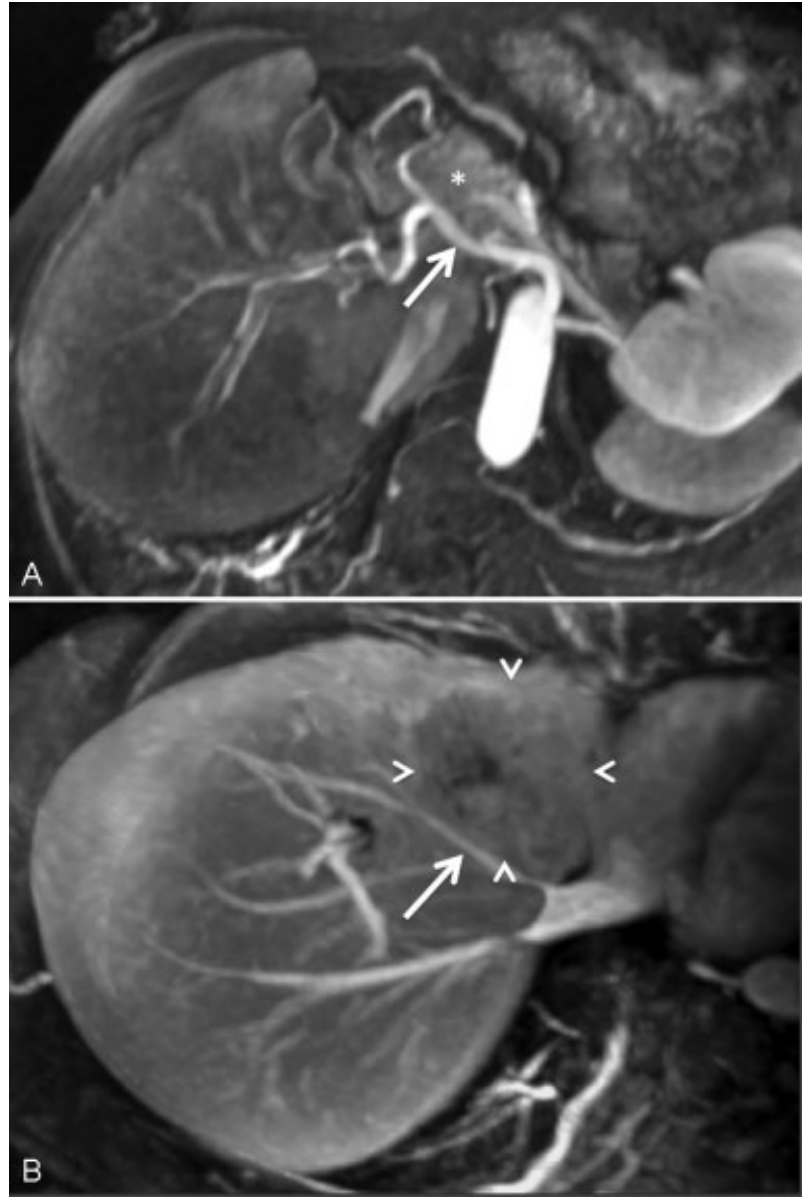

Fig. 4 (A) Contrast material-enhanced MRI that demonstrates relationship of cholangiocarcinoma (asterisk) to hepatic artery (white arrow). (B) Contrast material-enhanced MRI that demonstrates relationship of cholangiocarcinoma (white arrowheads) to middle hepatic vein (white arrow). MRI, magnetic resonance imaging.

\section{Endoscopic Ultrasound}

Endoscopic ultrasound (EUS) is commonly used to establish the diagnosis of CC especially when fine needle aspiration (FNA) biopsy is employed. ${ }^{72,73}$ The high-resolution image quality allows assessment of local tumor characteristics such as depth, stricture length, and ability to target liver lesions and regional lymph nodes inaccessible by percutaneous techniques. ${ }^{74,75}$ When combined with endoscopic retrograde cholangiopancreatography fine needle aspirates, EUS-FNA shows increased diagnostic accuracy (86\%) when compared with EUS-FNA (70\%) or endoscopic retrograde cholangiography biopsy $(67 \%)$ alone. ${ }^{76}$ The value of EUSFNA is limited by restricted needle penetration, cases of significant desmoplastic reaction, diminished cellularity, external compression of the bile duct by the tumor.

\section{Positron Emission Tomography and PET-Computed Tomography}

The role of positron emission tomography/CT (PET/CT) with 2-deoxy- $\left[{ }^{18} \mathrm{~F}\right]$ fluoro-D-glucose $\left({ }^{18} \mathrm{~F}-\mathrm{FDG}\right)$ is somewhat controversial, but emerging data suggest that they have a 

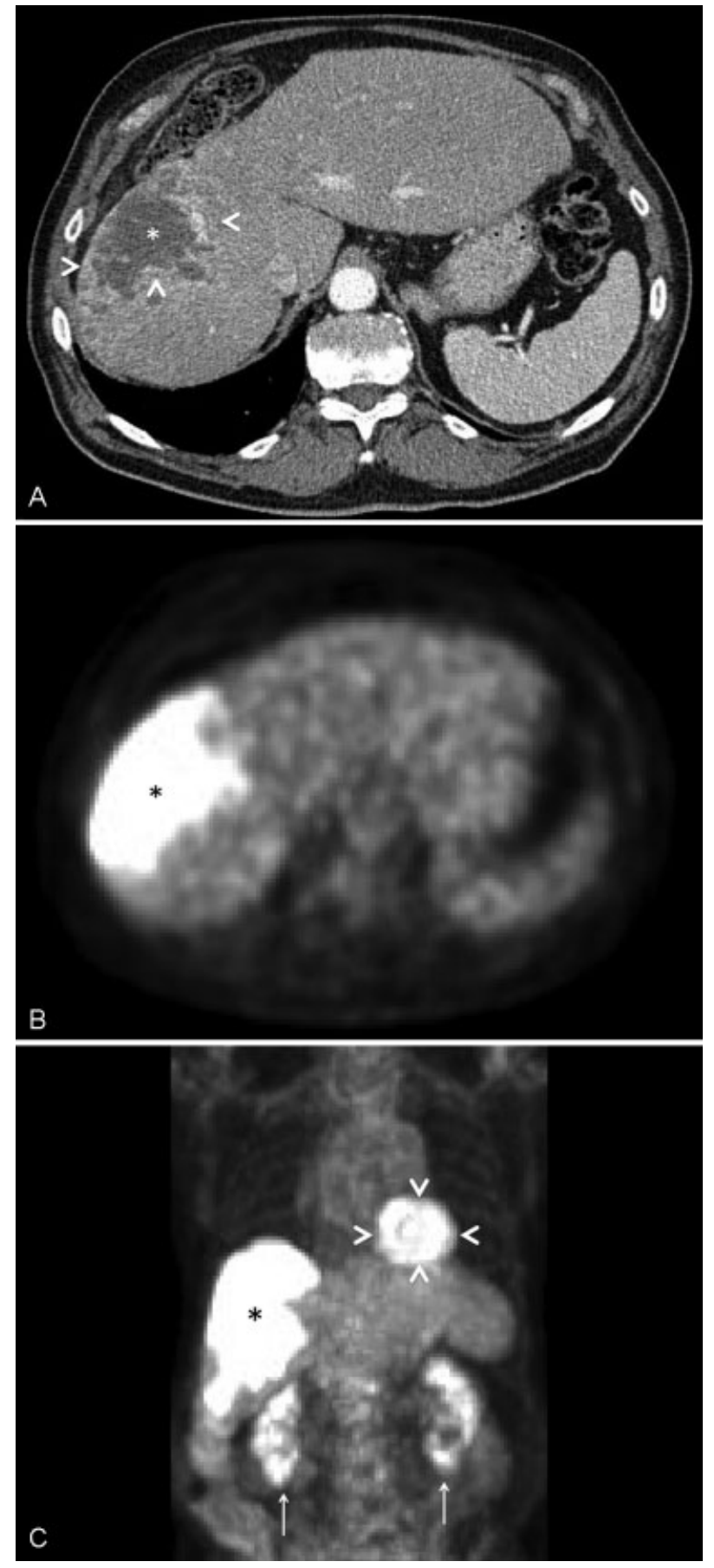

Fig. 5 (A) Contrast material-enhanced CT scan of the liver that demonstrates cholangiocarcinoma involving the right hepatic lobe (asterisk). The scan was obtained during the early portal-venous phase, when the enhancement is predominantly along the tumor margins (white arrowheads). (B) Axial positron emission tomography scan of the liver that demonstrates intense FDG activity of cholangiocarcinoma. (C) Coronal positron emission tomography scan of the liver that demonstrates intense FDG activity of cholangiocarcinoma (black asterisk). Normal FDG activity is noted in the heart (white arrowheads) and kidneys (white arrows). CT, computed tomography; FDG, fluoro-D-glucose.

potential role in the diagnosis and staging of CCs (-Fig. 5). Elias et al recently compared the diagnostic performance of FDG-PET/CT and CECT in patients with CC and found that FDG-PET/CT detected more intrahepatic malignant and extrahepatic metastases and had significant higher sensitivity, negative predictive value, and accuracy than CECT. ${ }^{77} \mathrm{PET} /$ $\mathrm{CT}$ also adds value in assessing the FDG activity outside the liver. In a recently published study by Jiang et al, the sensitivity, specificity, and accuracy of PET/CT and MRI in the diagnosis of regional lymph node metastases were 70/0 versus $50 \%, 91.7$ versus $83.3 \%$, and 81.8 versus $68.2 \%$, respectively. ${ }^{78}$ Other studies have found that FDG-PET is helpful in identifying regional and distant metastases but performed poorly in detecting mucinous variant of $\mathrm{CC}^{79}$ Choi et al have shown that PET/CT is useful in differentiating extrahepatic biliary malignancy from benign disease. ${ }^{80}$

\section{Conclusion}

CC is a disease with various imaging features based on multiple factors, including causative agents, growth pattern, and location within the hepatobiliary tree. Accurate detection, characterization, and assessment of the resectability of the tumor are the primary goals of imaging.

\section{References}

1 Bergquist A, von Seth E. Epidemiology of cholangiocarcinoma. Best Pract Res Clin Gastroenterol 2015;29(2):221-232

2 Shaib Y, El-Serag HB. The epidemiology of cholangiocarcinoma. Semin Liver Dis 2004;24(2):115-125

3 Lee JH, Yang HM, Bak UB, Rim HJ. Promoting role of Clonorchis sinensis infection on induction of cholangiocarcinoma during two-step carcinogenesis. Korean J Parasitol 1994;32(1):13-18

4 de Martel C, Plummer M, Franceschi S. Cholangiocarcinoma: descriptive epidemiology and risk factors. Gastroenterol Clin Biol 2010;34(3):173-180

5 Parkin DM, Ohshima H, Srivatanakul P, Vatanasapt V. Cholangiocarcinoma: epidemiology, mechanisms of carcinogenesis and prevention. Cancer Epidemiol Biomarkers Prev 1993;2(6):537-544

6 Bloom CM, Langer B, Wilson SR. Role of US in the detection, characterization, and staging of cholangiocarcinoma. Radiographics 1999;19(5):1199-1218

7 Byrling J, Andersson B, Andersson R, Marko-Varga G. Cholangiocarcinoma-current classification and challenges towards personalised medicine. Scand J Gastroenterol 2016;51(6):641-643

8 Singh P, Patel T. Advances in the diagnosis, evaluation and management of cholangiocarcinoma. Curr Opin Gastroenterol 2006;22(3):294-299

9 Hayashi A, Misumi K, Shibahara J, et al. Distinct clinicopathologic and genetic features of 2 histologic subtypes of intrahepatic cholangiocarcinoma. Am J Surg Pathol 2016;40(8):1021-1030

10 Ebata T, Kamiya J, Nishio H, Nagasaka T, Nimura Y, Nagino M. The concept of perihilar cholangiocarcinoma is valid. Br J Surg 2009; 96(8):926-934

11 Meyer CG, Penn I, James L. Liver transplantation for cholangiocarcinoma: results in 207 patients. Transplantation 2000;69(8): 1633-1637

12 Kijima H, Wu Y, Yosizawa T, et al. Pathological characteristics of early to advanced gallbladder carcinoma and extrahepatic cholangiocarcinoma. J Hepatobiliary Pancreat Sci 2014;21(7):453-458

13 Nakanuma Y, Sasaki M, Ikeda $\mathrm{H}$, et al. Pathology of peripheral intrahepatic cholangiocarcinoma with reference to tumorigenesis. Hepatol Res 2008;38(4):325-334

14 Jarnagin WR, Fong Y, DeMatteo RP, et al. Staging, resectability, and outcome in 225 patients with hilar cholangiocarcinoma. Ann Surg 2001;234(4):507-517, discussion 517-519 
15 Bismuth H, Corlette MB. Intrahepatic cholangioenteric anastomosis in carcinoma of the hilus of the liver. Surg Gynecol Obstet 1975;140(2):170-178

16 Ramos E. Principles of surgical resection in hilar cholangiocarcinoma. World J Gastrointest Oncol 2013;5(7):139-146

17 Ciombor KK, Goff LW. Current therapy and future directions in biliary tract malignancies. Curr Treat Options Oncol 2013;14(3): 337-349

18 Friman S. Cholangiocarcinoma-current treatment options. Scand J Surg 2011;100(1):30-34

19 Akamatsu N, Sugawara Y, Hashimoto D. Surgical strategy for bile duct cancer: Advances and current limitations. World J Clin Oncol 2011;2(2):94-107

20 Singh MK, Facciuto ME. Current management of cholangiocarcinoma. Mt Sinai J Med 2012;79(2):232-245

21 Nguyen KT, Steel J, Vanounou T, et al. Initial presentation and management of hilar and peripheral cholangiocarcinoma: is a node-positive status or potential margin-positive result a contraindication to resection? Ann Surg Oncol 2009;16(12):3308-3315

22 Polydorou AA, Cairns SR, Dowsett JF, et al. Palliation of proximal malignant biliary obstruction by endoscopic endoprosthesis insertion. Gut 1991;32(6):685-689

23 Brugge WR. Endoscopic techniques to diagnose and manage biliary tumors. J Clin Oncol 2005;23(20):4561-4565

24 Aljiffry M, Walsh MJ, Molinari M. Advances in diagnosis, treatment and palliation of cholangiocarcinoma: 1990-2009. World J Gastroenterol 2009;15(34):4240-4262

25 Lau SH, Lau WY. Current therapy of hilar cholangiocarcinoma. Hepatobiliary Pancreat Dis Int 2012;11(1):12-17

26 Butros SR, Shenoy-Bhangle A, Mueller PR, Arellano RS. Radiofrequency ablation of intrahepatic cholangiocarcinoma: feasability, local tumor control, and long-term outcome. Clin Imaging 2014;38(4):490-494

27 Sapisochin G, Facciuto M, Rubbia-Brandt L, et al; iCCA International ConsortiumLiver transplantation for "very early" intrahepatic cholangiocarcinoma: International retrospective study supporting a prospective assessment. Hepatology 2016;64(4):1178-1188

28 Hibi T, Itano O, Shinoda M, Kitagawa Y. Liver transplantation for hepatobiliary malignancies: a new era of "Transplant Oncology" has begun. Surg Today 2016. doi: 10.1007/s00595-016-1337-1

29 Schmeding M, Neumann UP. Liver transplant for cholangiocarcinoma: a comeback? Exp Clin Transplant 2015;13(4):301-308

30 Brandi G, Venturi M, Pantaleo MA, Ercolani GGICOCholangiocarcinoma: Current opinion on clinical practice diagnostic and therapeutic algorithms: a review of the literature and a long-standing experience of a referral center. Dig Liver Dis 2016;48(3):231-241

31 Sungkasubun P, Siripongsakun S, Akkarachinorate K, et al. Ultrasound screening for cholangiocarcinoma could detect premalignant lesions and early-stage diseases with survival benefits: a population-based prospective study of 4,225 subjects in an endemic area. BMC Cancer 2016;16:346

32 Koea J, Holden A, Chau K, McCall J. Differential diagnosis of stenosing lesions at the hepatic hilus. World J Surg 2004;28(5): 466-470

33 Neumaier CE, Bertolotto M, Perrone R, Martinoli C, Loria F, Silvestri E. Staging of hilar cholangiocarcinoma with ultrasound. J Clin Ultrasound 1995;23(3):173-178

34 Rosenthal SJ, Cox GG, Wetzel LH, Batnitzky S. Pitfalls and differential diagnosis in biliary sonography. Radiographics 1990;10(2): 285-311

35 Lupi L, Bighi S, Cervi PM, Marzola A. The CT and US aspects in hepatic cholangiocarcinoma due to thorium dioxide (thorotrast). A case report and review of the literature [in Italian]. Radiol Med (Torino) 1990;79(4):399-401

36 Colli A, Cocciolo M, Mumoli N, et al. Peripheral intrahepatic cholangiocarcinoma: ultrasound findings and differential diagnosis from hepatocellular carcinoma. Eur J Ultrasound 1998;7(2):93-99
37 Singh A, Chandrashekhara SH, Handa N, Baliyan V, Kumar P. "Periportal neoplasms"-a CT perspective: review article. $\mathrm{Br}$ J Radiol 2016;89(1060):20150756

38 Yata M, Suzuki K, Furuhashi N, Kawakami K, Kawai Y, Naganawa S. Comparison of the multidetector-row computed tomography findings of IgG4-related sclerosing cholangitis and extrahepatic cholangiocarcinoma. Clin Radiol 2016;71(3):203-210

39 Zhang H, Zhu J, Ke F, et al. Radiological imaging for assessing the respectability of hilar cholangiocarcinoma: a systematic review and meta-analysis. BioMed Res Int 2015;2015:497942

40 Seo H, Lee JM, Kim IH, et al. Evaluation of the gross type and longitudinal extent of extrahepatic cholangiocarcinomas on contrast-enhanced multidetector row computed tomography. J Comput Assist Tomogr 2009;33(3):376-382

41 Cho ES, Park MS, Yu JS, Kim MJ, Kim KW. Biliary ductal involvement of hilar cholangiocarcinoma: multidetector computed tomography versus magnetic resonance cholangiography. J Comput Assist Tomogr 2007;31(1):72-78

42 Lamba R, Fananapazir G, Corwin MT, Khatri VP. Diagnostic imaging of hepatic lesions in adults. Surg Oncol Clin N Am 2014;23(4): 789-820

43 Han JK, Choi BI, Kim AY, et al. Cholangiocarcinoma: pictorial essay of CT and cholangiographic findings. Radiographics 2002;22(1): 173-187

44 Apisarnthanarak P, Pansri C, Maungsomboon K, Thamtorawat S. The CT appearances for differentiating of peripheral, mass-forming cholangiocarcinoma and liver meatastases from colorectal adenocarcinoma. J Med Assoc Thai 2014;97(4):415-422

$45 \mathrm{Wu}$ XP, Ni JM, Zhang ZY, et al. Preoperative evaluation of malignant perihilar biliary obstruction: negative-contrast CT cholangiopancreatography and CT angiography versus MRCP and MR angiography. AJR Am J Roentgenol 2015;205(4):780-788

46 Sahani D, Saini S, Pena C, et al. Using multidetector CT for preoperative vascular evaluation of liver neoplasms: technique and results. AJR Am J Roentgenol 2002;179(1):53-59

47 Youngson GG, Driver CP, Mahomed AA, Duddalwar VA. Computed tomographic cholangiography in the diagnosis of bile duct injury in children. J Pediatr Surg 2003;38(11):E18-E20

48 Cabada Giadás T, Sarría Octavio de Toledo L, Martínez-Berganza Asensio MT, et al. Helical CT cholangiography in the evaluation of the biliary tract: application to the diagnosis of choledocholithiasis. Abdom Imaging 2002;27(1):61-70

49 Yeh BM, Breiman RS, Taouli B, Qayyum A, Roberts JP, Coakley FV. Biliary tract depiction in living potential liver donors: comparison of conventional MR, mangafodipir trisodium-enhanced excretory MR, and multi-detector row CT cholangiography-initial experience. Radiology 2004;230(3):645-651

50 Zandrino F, Benzi L, Ferretti ML, Ferrando R, Reggiani G, Musante F. Multislice CT cholangiography without biliary contrast agent: technique and initial clinical results in the assessment of patients with biliary obstruction. Eur Radiol 2002;12(5):1155-1161

51 Persson A, Dahlström N, Smedby O, Brismar TB. Three-dimensional drip infusion CT cholangiography in patients with suspected obstructive biliary disease: a retrospective analysis of feasibility and adverse reaction to contrast material. BMC Med Imaging 2006;6:1

52 Persson A, Dahlström N, Smedby O, Brismar TB. Volume rendering of three-dimensional drip infusion CT cholangiography in patients with suspected obstructive biliary disease: a retrospective study. Br J Radiol 2005;78(936):1078-1085

53 Hänninen EL, Pech M, Jonas S, et al. Magnetic resonance imaging including magnetic resonance cholangiopancreatography for tumor localization and therapy planning in malignant hilar obstructions. Acta Radiol 2005;46(5):462-470

54 Qian H, Li S, Ji M, Lin G. MRI characteristics for the differential diagnosis of benign and malignant small solitary hypovascular hepatic nodules. Eur J Gastroenterol Hepatol 2016;28(7): 749-756 
55 Joo I, Lee JM, Lee SM, Lee JS, Park JY, Han JK. Diagnostic accuracy of liver imaging reporting and data system (LI-RADS) v2014 for intrahepatic mass-forming cholangiocarcinomas in patients with chronic liver disease on gadoxetic acid-enhanced MRI. J Magn Reson Imaging 2016;44(5):1330-1338

56 Ciresa M, De Gaetano AM, Pompili M, et al. Enhancement patterns of intrahepatic mass-forming cholangiocarcinoma at multiphasic computed tomography and magnetic resonance imaging and correlation with clinicopathologic features. Eur Rev Med Pharmacol Sci 2015;19(15):2786-2797

57 Mamone G, Marrone G, Caruso S, et al. Intrahepatic mass-forming cholangiocarcinoma: enhancement pattern on Gd-BOPTA-MRI with emphasis of hepatobiliary phase. Abdom Imaging 2015; 40(7):2313-2322

58 Adam SZ, Parthasarathy S, Miller FH. Intrahepatic cholangiocarcinomas mimicking other lesions. Abdom Imaging 2015;40(7): 2345-2354

59 Chung YE, Kim MJ, Park YN, et al. Varying appearances of cholangiocarcinoma: radiologic-pathologic correlation. Radiographics 2009;29(3):683-700

60 Vilgrain V. Staging cholangiocarcinoma by imaging studies. HPB (Oxford) 2008;10(2):106-109

61 Yoon JH. Biliary papillomatosis: correlation of radiologic findings with percutaneous transhepatic cholangioscopy. J Gastrointestin Liver Dis 2013;22(4):427-433

62 Manfredi R, Barbaro B, Masselli G, Vecchioli A, Marano P. Magnetic resonance imaging of cholangiocarcinoma. Semin Liver Dis 2004; 24(2):155-164

63 Yin LL, Song B, Xu J, Li YC. Hilar cholangiocarcinoma: preoperative evaluation with a three dimensional volumetric interpolated breath-hold examination magnetic resonance imaging sequence. Chin Med J (Engl) 2007;120(8):636-642

64 Park DH, Kim MH, Lee SK, et al. Can MRCP replace the diagnostic role of ERCP for patients with choledochal cysts? Gastrointest Endosc 2005;62(3):360-366

65 Tse F, Barkun JS, Romagnuolo J, Friedman G, Bornstein JD, Barkun AN. Nonoperative imaging techniques in suspected biliary tract obstruction. HPB (Oxford) 2006;8(6):409-425

66 Romagnuolo J, Bardou M, Rahme E, Joseph L, Reinhold C, Barkun AN. Magnetic resonance cholangiopancreatography: a meta-analysis of test performance in suspected biliary disease. Ann Intern Med 2003;139(7):547-557

67 Masselli G, Gualdi G. Hilar cholangiocarcinoma: MRI/MRCP in staging and treatment planning. Abdom Imaging 2008;33(4): $444-451$
68 Zhong L, Li L, Yao QY. Preoperative evaluation of pancreaticobiliary tumor using MR multi-imaging techniques. World J Gastroenterol 2005;11(24):3756-3761

69 Zhong L, Xiao SD, Stoker J, Nj Tytgat G. Magnetic resonance cholangiopancreatography. Chin J Dig Dis 2004;5(4):139-148

70 Tsai TH, Hsu JS, Lai ML, Liu GC, Shih MC, Chen CY. Added value of diffusion-weighted imaging to MR cholangiopancreatography for the diagnosis of bile duct dilatations. Abdom Radiol (NY) 2016; 41(3):485-492

71 Wang J, Liu JJ, Liang YY, et al. Could diffusion-weighted imaging detect injured bile ducts of ischemic-type biliary lesions after orthotopic liver transplantation? AJR Am J Roentgenol 2012; 199(4):901-906

72 Ustundag Y, Alper E, Fusaroli P. EUS-FNA versus ERCP-guided sampling for suspected malignant biliary obstruction: which to choose? Gastrointest Endosc 2015;81(1):241-242

73 Téllez-Ávila FI, Bernal-Méndez AR, Guerrero-Vázquez CG, Martínez-Lozano JA, Ramírez-Luna MÁ. Diagnostic yield of EUS-guided tissue acquisition as a first-line approach in patients with suspected hilar cholangiocarcinoma. Am J Gastroenterol 2014; 109(8):1294-1296

74 Chang KJ. State of the art lecture: endoscopic ultrasound (EUS) and FNA in pancreatico-biliary tumors. Endoscopy 2006;38 (Suppl 1):S56-S60

75 Fritscher-Ravens A, Broering DC, Knoefel WT, et al. EUS-guided fine-needle aspiration of suspected hilar cholangiocarcinoma in potentially operable patients with negative brush cytology. Am J Gastroenterol 2004;99(1):45-51

76 Eloubeidi MA, Iseman DT, Chen VK, Vickers SM, Wilcox CM. Prevalence and significance of periduodenal venous collaterals in patients evaluated for pancreaticobiliary disorders by endosonography. Endoscopy 2003;35(12):1015-1019

77 Elias Y, Mariano AT Jr, Lu Y. Detection of primary malignancy and metastases with FDG PET/CT in patients with cholangiocarcinomas: lesion-based comparison with contrast enhanced CT. World J Nucl Med 2016;15(3):161-166

78 Jiang L, Tan H, Panje CM, Yu H, Xiu Y, Shi H. Role of 18F-FDG PET/CT imaging in intrahepatic cholangiocarcinoma. Clin Nucl Med 2016; 41(1):1-7

79 Fritscher-Ravens A, Bohuslavizki KH, Broering DC, et al. FDG PET in the diagnosis of hilar cholangiocarcinoma. Nucl Med Commun 2001;22(12):1277-1285

80 Choi EK, Yoo IeR, Kim SH, et al. The clinical value of dual-time point 18F-FDG PET/CT for differentiating extrahepatic cholangiocarcinoma from benign disease. Clin Nucl Med 2013;38(3):e106-e111 